\title{
Compromiso pleural en la leucemia de células plasmáticas. Reporte de un caso
}

\author{
JORGE YÁÑEZ V.*, VELIA SALDÍAS H.**, \\ ORLANDO DÍAZ P.* y FERNANDO SALDÍAS P.*
}

Pleural effusion in plasma cell leukemia. A case report

Multiple myeloma is a low malignant, non-Hodgkin's lymphoma, which is characterized by infiltration of the bone marrow by clonal proliferation of atypical plasma cells. Extramedullary manifestations are relatively rare. Serous effusions in multiple myeloma are uncommon $16 \%$ of cases) but a myelomatous pleural effusion occurring in these patients is extremely rare. Plasma cell leukemia, occurring either de novo or in patients with long standing multiple myeloma, is the least common type of plasma cell dyscrasia. The authors describe the course of plasmacellular leukemia in a 63-year-old male patient where the first manifestation of the disease was a bacteremic pneumococcal pneumonia and a contralateral pleural exudate with a cytological finding of plasma cells. The exudate disappeared after the first cycle of chemotherapy (vincristine, adriamycin, dexamethasone). After the third cycle of chemotherapy remission of the disease was recorded which was, however, short. After three month' remission the disease recurred, consequently underwent autologous bone marrow transplantation. The patient has maintained complete remission for 12 months after diagnosis. Pleural effusion is an unusual but important complication of multiple myeloma and does not necessarily carry the grave prognosis implied in previous reports.

Key words: Multiple myeloma, pleural effusion, plasma cell leukemia, chemotherapy.

\section{Resumen}

El mieloma múltiple es una neoplasia maligna de células plasmáticas que invade la médula ósea y otros tejidos. Las manifestaciones extramedulares son relativamente raras. El derrame pleural en el mieloma múltiple es poco frecuente (6\% de los casos), y el derrame pleural neoplásico es extremadamente raro. La leucemia de células plasmáticas, que se produce de novo o en pacientes con mieloma múltiple, es la variedad menos común de discrasia de células plasmáticas. Los autores describen el cuadro clínico de un paciente de 63 años con leucemia de células plasmáticas, donde la primera manifestación de la enfermedad fue una neumonía neumocócica bacteriémica asociado a un derrame pleural contralateral, que correspondió a un exudado predominio mononuclear. El examen citológico reveló abundantes células plasmáticas inmaduras en el líquido pleural y la sangre periférica. El derrame pleural desapareció después del primer ciclo de quimioterapia (vincristina, adriamicina, dexametasona). Después de tres meses de remisión, la enfermedad neoplásica recidivó, siendo el paciente sometido a trasplante autólogo de médula ósea. El paciente se ha mantenido en remisión completa un año después del diagnóstico. El derrame pleural es una complicación poco común, pero importante, del mieloma múltiple y no necesariamente conlleva un mal pronóstico.

Palabras clave: Mieloma múltiple, derrame pleural, leucemia de células plasmáticas, quimioterapia.

* Departamento de Enfermedades Respiratorias, Pontificia Universidad Católica de Chile.

** Alumna $7^{\circ}$ Año de Medicina, Universidad de los Andes. 


\section{Introducción}

El mieloma múltiple (MM) es una neoplasia maligna de células plasmáticas, representa el 15\% de las neoplasias hematológicas malignas, la cual invade la médula ósea y otros tejidos ${ }^{1}$. El compromiso torácico por MM se manifiesta por anomalías esqueléticas, plasmocitoma, infiltrados pulmonares y derrame pleural ${ }^{2}$. Se estima que un $6 \%$ de los pacientes con mieloma múltiple desarrollan derrame pleural en el curso de la enfermedad y rara vez es la manifestación ini$\mathrm{cial}^{3}$. Las principales causas de derrame pleural en el MM son benignas: insuficiencia cardíaca congestiva, insuficiencia renal, síndrome nefrótico, amiloidosis cardíaca, embolia pulmonar e infecciones ${ }^{4}$. El compromiso pleural neoplásico representa menos del $1 \%$ de los derrames pleurales, es secundario a la extensión pleural de un plasmocitoma pulmonar o de la pared torácica, diseminación hematógena $\mathrm{y} / \mathrm{u}$ obstrucción linfática, y le confiere un pronóstico ominoso a la enfermedad (sobrevida media de 4 meses) ${ }^{5}$. La leucemia de células plasmáticas (LCP) es una entidad infrecuente que puede ser primaria o secundaria a un mieloma múltiple ${ }^{6,7}$. Se caracteriza por su curso agresivo, pobre respuesta al tratamiento y sobrevida corta ${ }^{6}$. El compromiso pleural en esta entidad es excepcional describiéndose pocos casos en la literatura médica ${ }^{8,9}$, considerándose un factor de mal pronóstico.

Se presenta el caso clínico de un paciente con LCP diagnosticada en el contexto de una neumonía comunitaria grave con derrame pleural contralateral, el cual fue secundario a su patología hematológica, quien fue tratado con quimioterapia y trasplante autólogo de médula ósea con buena respuesta. A propósito de este caso, hemos revisado el cuadro clínico, la evolución y tratamiento del derrame pleural asociado a la neoplasia de células plasmáticas.

\section{Caso clínico}

Hombre de 63 años, fumador de 20 paquetes-año, portador de resistencia a insulina en tratamiento con metformina $850 \mathrm{mg} /$ día, consulta en el servicio de urgencia por cuadro de una semana de evolución caracterizado por compromiso del estado general, fiebre, calofríos, tos productiva, expectoración purulenta y disnea de esfuerzos rápidamente progresiva. En el examen físico destaca paciente en regulares condiciones generales, vigil, orientado, frecuencia cardíaca: 115 lat/min, presión arterial: 90/60 $\mathrm{mmHg}$, fre- cuencia respiratoria: 32 ciclos/min, temperatura: $38,5{ }^{\circ} \mathrm{C}, \mathrm{SaO}_{2}: 85 \%$ respirando aire ambiente. En el examen pulmonar se detecta matidez y disminución del murmullo pulmonar en la base izquierda y crepitaciones en el hemitórax derecho asociado a uso de musculatura accesoria. Se solicitó radiografía de tórax (Figura 1) que mostró foco de condensación en el lóbulo superior derecho y velamiento de seno costofrénico izquierdo por derrame pleural. Ingresa a UCI con el diagnóstico de neumonía comunitaria grave y shock séptico, evolucionando con aumento de los requerimientos de oxígeno, tiraje, respiración paradojal y compromiso del sensorio, por lo cual es intubado y conectado a ventilación mecánica. Fue manejado con aporte de cristaloides, drogas vasoactivas y tratamiento antibiótico biasociado (cefotaxima y levofloxacina).

En los exámenes de laboratorio destaca anemia normocítica normocrómica, leucocitosis con desviación a izquierda y presencia de células plasmáticas en sangre periférica (43\%), eritrosedimentación mayor de $140 \mathrm{~mm} / \mathrm{h}$, creatininemia: $1,57 \mathrm{mg} / \mathrm{dL}$, nitrógeno ureico: $35 \mathrm{mg} / \mathrm{dL}$, proteínas totales: $12,4 \mathrm{~g} / \mathrm{dL}$, albuminemia: $3,0 \mathrm{~g} / \mathrm{dL}$, globulinas séricas: 9,4 g/dL, LDH: 377 U/L, PCR: $15,5 \mathrm{mg} / \mathrm{dL}$ (Tabla 1). En los exámenes microbiológicos destaca el antígeno urinario de neumococo positivo y hubo desarrollo de Streptococcus pneumoniae resistente a eritromicina en los hemocultivos. El paciente fue evaluado por el equipo de hematología realizándose electroforesis de proteínas plasmáticas que mostró pico monoclonal en banda gamma, inmunoglobulina $\mathrm{G}$ sérica elevada: $6.060 \mathrm{mg} / \mathrm{dL}$ (VN: 694-1.618),

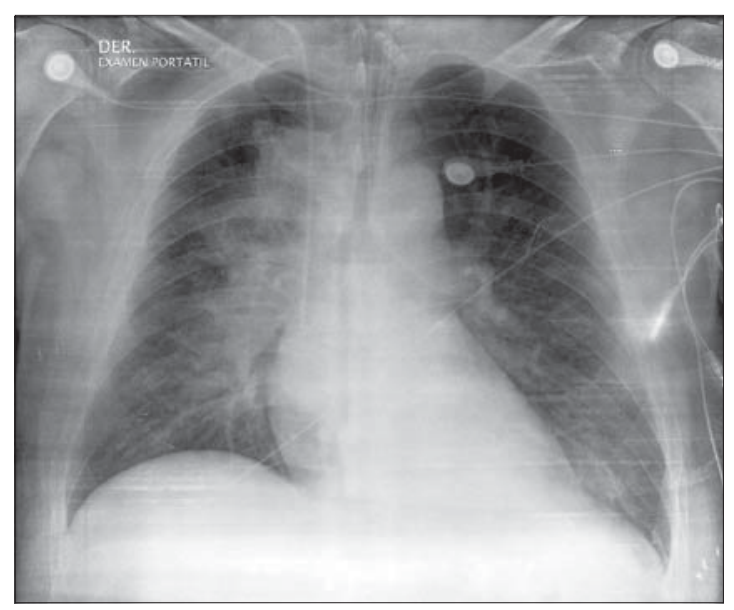

Figura 1. La radiografía de tórax de ingreso reveló foco de condensación pulmonar derecho y derrame pleural basal izquierdo. 
Tabla 1. Exámenes de laboratorio de paciente con leucemia de células plasmáticas y neumonía comunitaria grave por Streptococcus pneumoniae

\begin{tabular}{|c|c|c|}
\hline Fecha & Abril-07 & Julio-07 \\
\hline $\mathrm{FiO}_{2}$ & 0,50 & \\
\hline $\mathrm{pH}$ & 7,39 & \\
\hline $\mathrm{PaO}_{2}(\mathrm{mmHg})$ & 107 & \\
\hline $\mathrm{SaO}_{2}(\%)$ & 97 & \\
\hline $\mathrm{PaCO}_{2}(\mathrm{mmHg})$ & 33 & \\
\hline $\mathrm{HCO}_{3}^{-}(\mathrm{mEq} / \mathrm{L})$ & 21,4 & \\
\hline Lactato $(\mathrm{mmol} / \mathrm{L})$ & 2,9 & \\
\hline Hematocrito (\%) & 24,8 & 32,8 \\
\hline Hemoglobina (g/dL) & 8,4 & 11,0 \\
\hline Leucocitos $\left(\mathrm{mm}^{3}\right)$ & 18.800 & 19.600 \\
\hline Segmentados-baciliformes (\%) & $52-9$ & $90-1$ \\
\hline Células plasmáticas $\left(\mathrm{mm}^{3}\right)$ & 752 & 0 \\
\hline Plaquetas $\left(\mathrm{mm}^{3}\right)$ & 223.000 & 411.000 \\
\hline VHS (mm/h) & $>140$ & 16 \\
\hline PCR (mg/dL) & 15,5 & \\
\hline $\mathrm{Na}^{+}(\mathrm{mEq} / \mathrm{L})$ & 129 & 138 \\
\hline $\mathrm{K}^{+}(\mathrm{mEq} / \mathrm{L})$ & 3,8 & 4,4 \\
\hline $\mathrm{Cl}^{-}(\mathrm{mEq} / \mathrm{L})$ & 100 & 94 \\
\hline BUN (mg/dL) & 35 & 18 \\
\hline Creatininemia (mg/dL) & 1,57 & 0,68 \\
\hline Calcemia (mg/dL) & 8,1 & 9,6 \\
\hline Albúmina (g/dL) & 3,0 & 3,9 \\
\hline Glicemia (mg/dL) & 264 & 115 \\
\hline Protrombina (\%) & 34 & 99 \\
\hline TTPA (s) & 41,3 & 28,4 \\
\hline $\operatorname{Ig} \mathrm{G}(\mathrm{mg} / \mathrm{dL})$ & 6.060 & 619 \\
\hline $\operatorname{Ig} \mathrm{A}(\mathrm{mg} / \mathrm{dL})$ & 8 & 42 \\
\hline Ig M (mg/dL) & 4 & 45 \\
\hline Beta-2 microglobulina (mg/L) & 0,87 & 0,90 \\
\hline Mielograma: plasmoblastos (\%) & 90 & 1 \\
\hline
\end{tabular}

inmunoglobulinas A y M séricas disminuidas, y mielograma que reveló disminución de la serie eritroblástica y granulocítica, y aumento marcado de la serie agranulocítica a expensas de plasmoblastos (90\%). Se planteó el diagnóstico de leucemia de células plasmáticas. Se solicitó tomografía computarizada de tórax que reveló foco de condensación en los lóbulos superior e inferior derecho y derrame pleural izquierdo (Figura 2). Se realizó pleurocentesis diagnóstica y el estudio del líquido pleural demostró un exudado de predominio mononuclear con ADA elevado

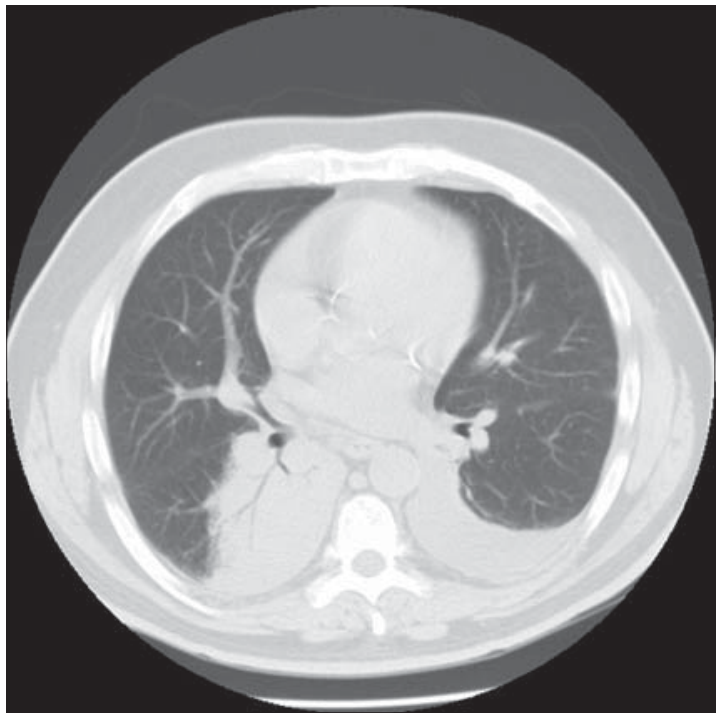

Figura 2. La tomografía computarizada de tórax reveló foco de condensación en lóbulo superior e inferior derecho y derrame pleural moderado izquierdo.

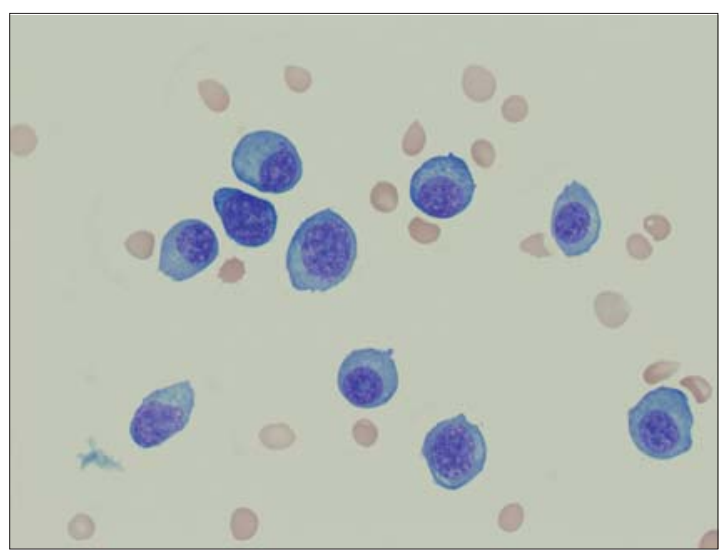

Figura 3. Paciente con leucemia de células plasmáticas variedad $\operatorname{IgG}$ que debutó con neumonía neumocócica y derrame pleural mielomatoso. La pleurocentesis demostró un exudado de predominio mononuclear y el examen citológico reveló numerosas células plasmáticas de formas maduras e inmaduras.

(64,3 U/L), pH: 7,39, lactato: $4 \mathrm{mmol} / \mathrm{L}$, los cultivos corrientes y de Koch fueron negativos, y el examen citológico reveló abundantes células plasmáticas inmaduras (Figura 3).

La evolución clínica fue favorable, con reducción y suspensión de las drogas vasopresoras, y desconexión del ventilador a los siete días, completando 14 días de tratamiento antibiótico. El paciente recibió primer ciclo de quimioterapia (vincristina, adriamicina y dexametasona), siendo bien tolerado. A los dos meses se controla con radiografía de tórax que mues- 
tra resolución completa del foco de condensación pulmonar derecho y derrame pleural contralateral; y en el mielograma se objetiva normalización de las series eritroblástica, granulocítica y agranulocítica, con remisión de la enfermedad neoplásica. Al sexto mes de inicio de la terapia, el paciente fue sometido a trasplante autólogo de médula ósea por persistencia de la enfermedad neoplásica, el procedimiento fue bien tolerado sin complicaciones significativas, continuando sus controles en hematología. El paciente se mantiene en buenas condiciones generales y sin evidencias de recidiva tumoral un año después de realizado el diagnóstico.

\section{Discusión}

El mieloma múltiple corresponde a una proliferación maligna de células plasmáticas que invade la médula ósea y otros tejidos ${ }^{1,2}$. Suele ser una enfermedad del adulto mayor, con una edad media de pesquisa entre 65 y 70 años, y se manifiesta por dolores óseos, fracturas patológicas, insuficiencia renal, hipercalcemia, lesiones osteolíticas, osteoporosis, anemia normocítica normocrómica e infecciones respiratorias por microorganismos capsulados (S. pneumoniae, $H$. influenzae), con presencia de una proteína monoclonal en suero $\mathrm{y} / \mathrm{u}$ orina ${ }^{1-3}$.

En 2003, el Grupo Internacional de Trabajo sobre Mieloma (International Myeloma Working Group) acordó los criterios diagnósticos del mieloma sintomático, mieloma asintomático y gammopatía monoclonal de significancia indeterminada (MGUS) ${ }^{10}$. En la gammopatía monoclonal de significado incierto, la proteína monoclonal o paraproteína sérica es menor de $30 \mathrm{~g} / \mathrm{L}$ y el recuento de células plasmáticas clonales es menor de $10 \%$ en las biopsias de médula ósea, sin evidencias de mieloma múltiple, otro trastorno proliferativo de linfocitos B o amiloidosis. En el mieloma múltiple asintomático (smouldering myeloma) la proteína monoclonal sérica es mayor o igual a $30 \mathrm{~g} / \mathrm{L}$ y/o el recuento de células plasmáticas clonales en las biopsias de médula ósea es mayor o igual a 10\%, sin evidencias de daño a órganos o tejidos relacionadas con el mieloma, que típicamente se manifiesta por hipercalcemia, insuficiencia renal, anemia, lesiones óseas, infecciones graves frecuentes, amiloidosis o síndrome de hiperviscosidad atribuibles a la proliferación de células plasmáticas. El mieloma múltiple sintomático requiere pruebas de daño a órganos o tejidos relacionados a la proliferación de células plasmáticas. Nuestro pa- ciente cumplía con los siguientes criterios diagnósticos: plasmocitosis medular mayor de $30 \%$, componente monoclonal en suero (IgG mayor de $3,5 \mathrm{~g} / \mathrm{dL})$ y anemia $(\mathrm{Hb}<10 \mathrm{~g} / \mathrm{dL})$.

La leucemia de células plasmáticas es una variante rara del mieloma múltiple, constituyendo el $2-3 \%$ de todos los mielomas ${ }^{6-9}$. Se define por la presencia de más de $20 \%$ de células plasmáticas en el recuento total de leucocitos o más de 2.000 células plasmáticas $/ \mu \mathrm{L}$ en sangre periférica $^{6,7}$. La edad de presentación fluctúa entre los 50 y 70 años de edad, con predominio del sexo femenino. Existe una forma primaria, cuando la leucemización está presente en el momento del diagnóstico como ocurrió en nuestro caso, y $40 \%$ de los casos corresponde a formas secundarias, cuando aparece como consecuencia de la transformación de un mieloma múltiple ya conocido. El compromiso extramedular se presenta en alrededor del $10 \%$ de los casos y se caracteriza por la presencia de anemia, hipercalcemia, trombocitopenia, falla renal, adenopatías, hepatoesplenomegalia y compromiso óseo ${ }^{6-9}$. El componente monoclonal sérico y/o urinario suele ser de menor cuantía que en los MM típicos, mientras que la insuficiencia renal es común. La sobrevida media de la LCP primaria con tratamiento quimioterápico estándar son 7 meses y de la forma secundaria sólo 2 meses $^{6}$.

El compromiso torácico del mieloma múltiple puede presentarse como lesiones óseas, plasmocitoma tisular, infiltrados pulmonares y derrame pleural $^{1-3}$. El derrame pleural se presenta en alrededor de $6 \%$ de los pacientes, siendo la etiología multifactorial: infeccioso, insuficiencia renal, síndrome nefrótico, embolia pulmonar, insuficiencia cardíaca secundaria a amiloidosis, neoplasias secundarias e infiltración por células plasmáticas ${ }^{3-5}$.

La infiltración mielomatosa se presenta en menos del $1 \%$ de los casos de MM con derrame pleural, postulándose los siguientes mecanismos en su generación: extensión desde lesiones óseas o parenquimatosas adyacentes, implantación directa, infiltración de nódulos linfáticos en el mediastino con obstrucción linfática, y el aumento en la producción local de inmunoglobulinas con aumento de la presión coloido-osmótica en el espacio pleural y reducción en la reabsorción del líquido pleural ${ }^{4,5}$.

El derrame pleural asociado a MM es un exudado de predominio mononuclear con niveles elevados de la enzima adenosin-deaminasa y, ocasionalmente, aumento del recuento de eosinófilos $^{3-5}$. El $80 \%$ de los casos están asociados a MM productor de IgA, debido a su mayor ten- 
dencia a invadir estructuras extra-óseas, y el resto son productores de IgG. Se han descrito casos aislados asociados a MM productores de IgD y de cadenas livianas ${ }^{11-13}$.

Los criterios diagnósticos del derrame pleural por infiltración mielomatosa $\operatorname{son}^{4,5}$ : a) Demostración de pico monoclonal en electroforesis de líquido pleural; b) Detección de células plasmáticas en el examen citológico de líquido pleural; c) Confirmación histológica, esta última puede fallar por el compromiso no homogéneo de la pleura. En el mieloma múltiple y la leucemia de células plasmáticas, la presencia de derrame pleural, se asocia a un pronóstico adverso, con una sobrevida media que no supera los cuatro meses $^{3-5,11,14}$

El tratamiento del mieloma múltiple y la leucemia de células plasmáticas incluye la quimioterapia con VAD (vincristina, adriamicina y dexametasona), la talidomida, el CC-5013 (Revimid), agentes alquilantes e incluso el trasplante autólogo de médula ósea, como aconteció en nuestro paciente $^{15-17}$. El pronóstico de la leucemia de células plasmáticas primaria ha mejorado con el trasplante de médula ósea y terapias nuevas como Bortezomib combinado con dexametasona con o sin adriamicina ${ }^{18-20}$. En pacientes con disnea importante se debe considerar la evacuación del líquido pleural y pleurodesis química, considerando que existe un elevado riesgo de recurrencia.

\section{Bibliografía}

1.- BATAILLE R, HAROUSSEAU J L. Multiple myeloma. N Engl J Med 1997; 336: 1657-64.

2.- KYLE R A. Multiple myeloma: review of 869 cases. Mayo Clin Proc 1975; 50: 29-40.

3.- KINTZER J S Jr, ROSENOW E C $3^{\text {rd }}$, KYLE R A. Thoracic and pulmonary abnormalities in multiple myeloma. A review of 958 cases. Arch Intern Med 1978; 138: 727-30.

4.- RODRÍGUEZ J N, PEREIRA A, MARTÍNEZ J C, CONDE J, PUJOL E. Pleural effusion in multiple myeloma. Chest 1994; 105: 622-34.

5.- ALEXANDRAKIS M G, PASSAM F H, KYRIAKOU D S, BOUROS D. Pleural effusions in hematologic malignancies. Chest 2004; 125: 1546-55.

6.- JIMÉNEZ-ZEPEDA V H, DOMÍNGUEZ V J. Plasma cell leukemia: a rare condition. Ann Hematol 2006; 85: 263-7.

Correspondencia a:

Dr. Fernando Saldías Peñafiel

Departamento de Enfermedades Respiratorias

Pontificia Universidad Católica de Chile

Marcoleta 352 - $1^{\text {er }}$ Piso

Santiago, Chile

E-mail: fsaldias@med.puc.cl
7.- KHOSRAVI SHAHI P. Leucemia de células plasmáticas: variante rara del mieloma múltiple. Caso clínico. An Med Interna (Madrid) 2005; 22: 532-4.

8.- GUZZINI F, CEPPI M, COZZI C, GIUSSANI R, TOMASI A. Plasma cell leukemia originating with pleural effusion. Minerva Med 1989; 80: 177-80.

9.- GARCÍA-SANZ R, ORFAO A, GONZÁLEZ M, TABERNERO M D, BLADÉ J, MORO M J, et al. Primary plasma cell leukemia: clinical, immunophenotypic, DNA ploidy, and cytogenetic characteristics. Blood 1999; 93: 1032-7.

10.- THE INTERNATIONAL MYELOMA WORKING GROUP. Criteria for the classification of monoclonal gammopathies, multiple myeloma and related disorders: a report of the International Myeloma Working Group. Br J Haematol 2003; 121: 749-57.

11.- KIM Y M, LEE K K, OH H S, PARK S K, WON J H, HONG D S, et al. Myelomatous effusion with poor response to chemotherapy. J Korean Med Sci 2000; 15: 243-6.

12.- MAACHI M, FELLAHI S, DIOP M E, FRANCOIS T, CAPEAU J, BASTARD J P. Pleural effusion as a first sign of Ig D lambda multiple myeloma. Ann Med Interne (París) 2003; 154: 70-2.

13.- SHIRAI T, HASHIZUME I, KASAMATSU N, NAKAMURA A, YAMATANI $H$, HANZAWA $S$, et al. A case of Bence-Jones protein-lambda positive multiple myeloma complicated by abnormal plasma cells in pleural effusion. Nihon Kokyuki Gakkai Zasshi 1998; 36: 176-81.

14.- KAMBLE R, WILSON C S, FASSAS A, DESIKAN R, SIEGEL D S, TRICOT G, et al. Malignant pleural effusion of multiple myeloma: prognostic factors and outcome. Leuk Lymphoma 2005; 46: 1137-42.

15.- ANDERSON H, SCARFFE J H, RANSON M, YOUNG R, WIERINGA G S, MORGENSTERN G R, et al. VAD chemotherapy as remission induction for multiple myeloma. Br J Cancer 1995; 71: 326-30.

16.- BARLOGIE B, SHAUGHNESSY J, TRICOT G, JACOBSON J, ZANGARI M, ANAISSIE E, et al. Treatment of multiple myeloma. Blood 2004; 103: 20-32.

17.- BARLOGIE B. Thalidomide and CC-5013 in multiple myeloma: the University of Arkansas experience. Semin Hematol 2003; 40 (4 Suppl 4): 33-8.

18.- SACCARO S, FONSECA R, VEILLON D M, COTELINGAM J, NORDBERG M L, BREDESON C, et al. Primary plasma cell leukemia: Report of 17 new cases treated with autologous or allogeneic stem-cell transplantation and review of the literature. Am J Hematol 2005; 78: 288-94.

19.- KIM S J, KIM J, CHO Y, SEO B K, KIM B S. Combination chemotherapy with Bortezomib, Cyclophosphamide and Dexamethasone may be effective for plasma cell leukemia. Jpn J Clin Oncol 2007; 37: 382-4.

20.- RICHARDSON P G, MITSIADES C, SCHLOSSMAN R, MUNSHI N, ANDERSON K. New drugs for myeloma. Oncologist 2007; 12: 664-89. 